\title{
Turismo Comunitario, Alternativa De Desarrollo Turístico Estudio De Caso: Turismo Rural Comunitario Para La Parroquia Cacha, Cantón Riobamba, Provincia De Chimborazo - Ecuador
}

\author{
Juan Carlos Carrasco Baquero
}

Docente - Investigador de la Facultad de Recursos Naturales ESCUELA SUPERIOR POLITÉCNICA DE CHIMBORAZO - ECUADOR Laura Beatriz Sucuy Janeta

Estudiante, Escuela de Ingeniería en Ecoturismo, Facultad de Recursos Naturales

ESCUELA SUPERIOR POLITÉCNICA DE CHIMBORAZO - ECUADOR Carlos Renato Chávez Velásquez

Docente - Investigador de la Facultad de Recursos Naturales ESCUELA SUPERIOR POLITÉCNICA DE CHIMBORAZO - ECUADOR

doi: 10.19044/esj.2016.v12n17p173 URL:http://dx.doi.org/10.19044/esj.2016.v12n17p173

Abstract

Ecuador is recognized as a country with the richest biodiversity on the planet, especially in relation to its size. For its variety of natural and cultural settings, it is even considered a magical place. Tourism is currently an activity that is generating considerable foreign income and employment for Ecuador, as well as maintaining and restoring cultural traditions and natural areas in sustainable ways. Rural, community-based tourism is one form that attempts to integrate community members with tourists in an intercultural setting, while ensuring sufficient management of the experience that natural resources, heritage values and cultural rights are preserved. In Chimborazo, a larger percentage of the indigenous population than in any other province is engaged in community-based tourism, creating experiences that complement tourist visits to natural attractions. Within this context is the rural parish of Cacha, with its unique natural landscapes and rich history, considered the origin of the Great Puruwá Nation. Following a market study on generating community-based tourism in Cacha, we conclude that the concept has wide local acceptance and that there is a high demand among tourists who would be interested in learning about this region and enjoying its benefits. Additionally, marketing tourist products assists communities in maintaining their traditions and motivates young people to generate new economic activity. 
Keywords: Community Tourism, Cultural Events, Chimborazo, Cacha

\section{Resumen}

El Ecuador es considerado como el país con mayor biodiversidad del planeta en relación a su tamaño, sus múltiples escenarios en naturaleza y cultura lo convierten en un país mágico. El turismo en la actualidad es una actividad que estimula generación de divisas y empleo, mantiene y recupera las manifestaciones culturales y naturales de una forma sostenible, el turismo rural comunitario es una modalidad de turismo que busca integrar a las comunidades con los visitantes desde una perspectiva intercultural, garantizando el manejo adecuado de los recursos y la valoración de sus patrimonios y derechos culturales. Según el Instituto Nacional de Estadísticas y Censo (INEC), 2010, la provincia de Chimborazo presenta el mayor porcentaje de población indígena del país $(37,99 \%)$ dentro de su jurisdicción y agrupada principalmente en comunidades, (el Ecuador presenta varios niveles de organización sociodemográfica: Región, Provincia, Cantón, Parroquia y Comunidad), que complementado con sus atractivos naturales hacen factible el turismo comunitario en esta localidad. La Parroquia Rural Cacha cuenta con singulares paisajes naturales y una gran riqueza histórica, considerada como la raíz de la Gran Nación Puruwá. Se realizó un estudio de mercado, el mismo que demuestra que el concepto de turismo comunitario tiene gran aceptación, y se ha determinado que existe una alta demanda de turistas que les gustaría conocer este poblado y disfrutar de sus beneficios. Además que con la operación de los productos se promueve a las comunidades a conservar sus tradiciones e incentivar a los jóvenes a ser generadores de nuevos proyectos.

Palabras clave: Turismo comunitario, manifestaciones culturales, Chimborazo, Cacha

\section{Introducción}

Se considera al turismo como una actividad con eficientes réditos económicos a nivel mundial, considerando que la contribución total del viaje y el turismo a la economía global en el año 2015 fue de 7,2 billones de dólares lo que equivale al 9,8\% del PIB de toda la economía de ese año, aportando a la creación de 2,5 millones de puestos de trabajo nuevos directamente en el sector en ese año, y en total se crearon 7,2 millones de empleos nuevos como resultado de la actividad directa, indirecta e inducida total (World Travel \& Tourism Counsil, 2015:1). A nivel global, la industria del viaje y el turismo superó el crecimiento de la mayoría de los sectores líderes, como: la automoción, las TIC, los servicios financieros, la industria 
aeroespacial y extractiva; superados únicamente por los sectores como la electrónica de consumo y las máquinas herramienta (Organización Mundial del Turismo, 2015). Por esta razón el turismo ha tenido una expansión acelerada a nivel mundial, en donde los destinos turísticos tanto tradicionales como nuevos se enfrentan a una presión cada vez mayor sobre sus entornos naturales, culturales y socioeconómicos (Organización Mundial del Turismo, 2001, pág. 3).

En Ecuador el turismo se ha convertido en un eje generador de economía, este sector actualmente ocupa el tercer puesto en las exportaciones no petroleras después del banano y el camarón (Coordinación General de Estadística e Investigación, 2014:15). Este pequeño País está dividido en cuatro regiones (Costa, Sierra o Andes, Amazonia y Galápagos) las cuales poseen una alta biodiversidad, un alta riqueza cultural y una gran variabilidad climática, haciendo de este País un potencial turístico, y de esta manera logrando atraer a más de un millón de visitantes al año (Boletín de Estadísticas Turísticas, 2014:9).

El turismo en el Ecuador en el año 2014 receptó la visita de 1`557.006 de turistas (Coordinación General de Estadística e Investigación del Ministerio de Turismo del Ecuador, 2015, págs. 7,15); por lo que se demuestra que es una fuente generadora de empleo con la creación de 405.819 plazas en el primer trimestre del año 2015, es decir un incremento de 66.149 plazas $(16,3 \%)$ en relación al mismo periodo del año 2013 (Coordinación General de Estadística e Investigación del Ministerio de Turismo del Ecuador, 2015, pág. 2).

Ecuador se caracteriza por ser un país pluricultural y multiétnico conformado por 14 nacionalidades y 18 pueblos (CODENPE, 2012:1), cada una tan diferente de la otra en lo que respecta a la flora, fauna y costumbres de la gente (Esteban Ruiz Ballesteros y Doris Solís Carrión, 2007, 32). Además el estado ecuatoriano reconoce en su Constitución Política la diversidad cultural y los derechos de los pueblos y por tanto el respeto hacia los diferentes sectores sociales (Constitución de la República del Ecuador, 2008:41). La Nacionalidad Kichwa de la sierra, abarca a la mayoría de pueblos del país, en donde aún se conservan sus manifestaciones culturales propias y específicas como festividades, astronomía, arquitectura, gastronomía y más (CODENPE, 2012:1). El concepto de turismo comunitario se fundamenta en la creación de productos turísticos bajo el principio básico de la necesaria participación de la comunidad local (Sampaio, 2007), esta forma de turismo se presenta como una oportunidad de puentes entre la rentabilidad económica, la conservación del ambiente y el respeto socio cultural (Cruz Blasco, 2012), también considerada como aquella actividad turística en donde el manejo, toma de decisiones, y participación accionaria está en manos parcial o totalmente de las 
comunidades asentadas en un área natural apropiada para esta actividad (Prieto, 2011).

La provincia de Chimborazo posee un alto grado de diversidad tanto natural como cultural, lo que la convierte en una potencia turística (Gobierno Autónomo descentralizado Chimborazo; 2011), que busca articularse mediante políticas de gobierno que están enmarcadas en el Plan Nacional del Buen Vivir 2013-2017 y en la Constitución de la República del Ecuador (SENPLADES, 2013).

Cacha es una parroquia importante, con atractivos turísticos poco conocidos y a pesar de sus limitantes económicos, sus habitantes aún mantienen sus rasgos culturales Puruwaes, lo que indudablemente con su historia y naturaleza constituye una ventaja comparativa para el desarrollo turístico de la parroquia.

Mediante el estudio de mercado se determinó que el turismo comunitario cuenta con una gran aceptación para su realización en esta Parroquia. Mediante la cual el Centro Turístico Cultural Pucará Tambo impulsa el turismo dentro del territorio, promueve el rescate de la cultura, maneja sosteniblemente su patrimonio, genera fuentes de trabajo para sus pobladores y oferta además productos y servicios con materia prima y mano de obra local.

\section{Metodología}

Para la elaboración del presente estudio se aplicaron los métodos y técnicas de la investigación de campo y documental, de la siguiente manera:

\section{utilizó:}

\section{Atractivos naturales}

Los atractivos naturales y culturales de uso turístico de la Parroquia Cacha fueron actualizadas mediante salidas de campo a cada sitio de interés y aplicando la metodología propuesta por el Ministerio de Turismo del Ecuador (MINTUR), 2004; la cual permite obtener información detallada enfocada en el aprovechamiento sostenible y evitando la explotación de estos recursos.

\section{Patrimonio cultural inmaterial}

Para la actualización del registro de inventario de Patrimonio Cultural Inmaterial se utilizó la metodología propuesta por el Instituto Nacional de Patrimonio Cultural (INPC), 2011; en donde se realizaron salidas de campo para constatar cada uno de estos bienes, con lo que se propicia el respeto a la diversidad cultural y se fomenta el diálogo intercultural.

- Para el análisis de la demanda se realizó: 


\section{Segmentación del mercado}

Para definir el producto de turismo rural comunitario se analizó como potenciales clientes al total de turistas nacionales y extranjeros que llegan a la ciudad de Riobamba.

\section{Universo}

El universo de estudio según la segmentación de mercado es de 9046 de los cuales el 72\% (6513) son turistas extranjeros y 28\% (2533) turistas nacionales. (MINTUR, 2014).

\section{Muestra}

Para determinar la muestra se utilizó la fórmula de poblaciones finitas con un margen de error del 5\%; del total de encuestas por medio de una regla de tres se distribuye la cantidad para los dos segmentos.

Dónde:

$$
n=\frac{N(P * Q)}{(N-1)\left(\frac{e}{Z}\right)^{2}+(P * Q)}
$$

$\mathrm{n}=$ Tamaño de la muestra

$\mathrm{N}=$ Universo de estudio

$\mathrm{p}=(0,5)$ Probabilidad de ocurrencia

$\mathrm{q}=(0,5)$ Probabilidad de no ocurrencia

$\mathrm{e}=(5 \%)$ Margen de error

$\mathrm{z}=(1,96)$ Nivel de confianza

$n=\frac{9046(0,5 * 0,5)}{(9046-1)\left(\frac{0,05}{1,96}\right)^{2}+(0,5 * 0,5)}=369$

Dando como resultado 369 personas a ser encuestadas y entrevistadas.

Tabla No 1 . Clasificación de los turistas

\begin{tabular}{ccc}
\hline Variables & Frecuencia & Porcentaje \\
\hline Nacional & 103 & $28 \%$ \\
\hline Extranjero & 266 & $72 \%$ \\
\hline Total & $\mathbf{3 6 9}$ & $\mathbf{1 0 0 \%}$ \\
\hline
\end{tabular}

Se obtiene como resultado un tamaño muestral de 369 encuestas, 103 para turistas nacionales y 266 para turistas extranjeros, las mismas que se aplicaron a los dos segmentos de mercado en las principales calles de la ciudad de Riobamba durante el mes de Diciembre de 2015 y Enero de 2016.

\section{Instrumento de investigación}

La técnica utilizada para la investigación de campo fue la encuesta y como instrumento se elaboró un cuestionario (Ver Anexo 1) tanto para turistas nacionales (Castellano) y para turistas extranjeros (Inglés).

\section{- $\quad$ Para el diseño del producto}


Se tomó como base el análisis de los atractivos turísticos, servicios e infraestructura existentes en la zona. Se identificó la planta turística necesaria para las actividades, así como las necesidades y requerimientos de las instalaciones, con lo que se elaboró paquetes turísticos

\section{Resultados}

\section{Actualización del inventario de Recursos Naturales y Manifestaciones Culturales}

Tabla No 2. Resumen de los Atractivos de la Parroquia Cacha

\begin{tabular}{|c|c|c|c|c|c|c|c|c|}
\hline \multirow[b]{2}{*}{$\mathbf{N}^{\circ}$} & \multirow{2}{*}{$\begin{array}{l}\text { NOM } \\
\text { BRE } \\
\text { DEL } \\
\text { ATRA } \\
\text { CTIV } \\
\text { O }\end{array}$} & \multicolumn{3}{|c|}{ CLASIFICACIÓN } & \multirow{2}{*}{$\begin{array}{c}\text { UBICACIÓ } \\
\mathbf{N}\end{array}$} & \multirow[b]{2}{*}{ DESCRIPCIÓN BREVE } & \multirow{2}{*}{$\begin{array}{l}\text { ESTADO DE } \\
\text { CONSERVAC } \\
\text { IÓN }\end{array}$} & \multirow[b]{2}{*}{ JRQ } \\
\hline & & $\begin{array}{l}\text { Catego } \\
\text { ría }\end{array}$ & Tipo & $\begin{array}{l}\text { Subtip } \\
\text { o }\end{array}$ & & & & \\
\hline 1 & $\begin{array}{l}\text { Cerro } \\
\text { Chuyu } \\
\text { g }\end{array}$ & $\begin{array}{l}\text { Sitio } \\
\text { Natura } \\
\quad 1\end{array}$ & $\begin{array}{l}\text { Mon } \\
\text { taña }\end{array}$ & Cerro & $\begin{array}{c}X: 754780 \\
\text { Y: } 9807585\end{array}$ & $\begin{array}{l}\text { Su nombre proviene del idioma Tsáchila } \\
\text { que significa “salir del recién muerto”. } \\
\text { Presenta una gran inclinación, con suelo } \\
\text { de origen volcánico, ofrece una belleza } \\
\text { paisajística y una alta riqueza en avifauna } \\
\text { y flora silvestre. }\end{array}$ & Alterado & I \\
\hline 2 & $\begin{array}{l}\text { Cerro } \\
\text { Igno }\end{array}$ & $\begin{array}{l}\text { Sitio } \\
\text { Natura } \\
\quad 1\end{array}$ & $\begin{array}{l}\text { Mon } \\
\text { taña }\end{array}$ & Cerro & $\begin{array}{c}X: 753827 \\
Y: 9812472\end{array}$ & $\begin{array}{l}\text { Cerro de mediana inclinación, posee una } \\
\text { vegetación escasa debido a que el suelo } \\
\text { está formado por cancagua, desde la cima } \\
\text { se puede observar la ciudad de } \\
\text { Riobamba, los nevados Chimborazo, } \\
\text { Carihuairazo, Tungurahua, El Altar, } \\
\text { Sangay y el cerro Chuyug. }\end{array}$ & Alterado & I \\
\hline 3 & $\begin{array}{l}\text { Lagun } \\
\text { a } \\
\text { Verde } \\
\text { Kocha }\end{array}$ & $\begin{array}{l}\text { Sitio } \\
\text { Natura } \\
\quad 1\end{array}$ & $\begin{array}{c}\text { Amb } \\
\text { iente } \\
\text { lacus } \\
\text { tre }\end{array}$ & Cocha & $\begin{array}{c}X: 758433 \\
Y: 9810807\end{array}$ & $\begin{array}{l}\text { Pequeña laguna que con el paso del } \\
\text { tiempo va disminuyendo su tamaño, } \\
\text { presenta la forma de una guitarra por lo } \\
\text { que sus pobladores han tejido creencias } \\
\text { sobre esta. El agua es oscura y turbia, } \\
\text { alrededor y dentro de la laguna crece } \\
\text { totora (Schoenoplectus californicus), } \\
\text { sigse (Cortaderia sp), paja (Gramíneas) } \\
\text { y entre otros. El sitio es utilizado como } \\
\text { bebedero de los animales de pasto. }\end{array}$ & Conservado & I \\
\hline 4 & $\begin{array}{c}\text { Kunuk } \\
\text { Pokio }\end{array}$ & $\begin{array}{l}\text { Sitio } \\
\text { Natura } \\
\quad 1\end{array}$ & Ríos & Fuente & $\begin{array}{c}X: 760907 \\
Y: 9811265\end{array}$ & $\begin{array}{l}\text { Es una fuente de agua de escaso caudal y } \\
\text { de agua transparente que brota desde la } \\
\text { tierra. En horas de la madrugada el agua } \\
\text { de esta fuente es relativamente caliente. } \\
\text { Este sitio tiene un gran valor significativo } \\
\text { para la comunidad debido que aquí se } \\
\text { realizan baños de purificación de los } \\
\text { pobladores. }\end{array}$ & Conservado & I \\
\hline 5 & $\begin{array}{l}\text { Balnea } \\
\text { rio de } \\
\text { Hualco } \\
\text { po } \\
\text { Duchic } \\
\text { ela }\end{array}$ & $\begin{array}{l}\text { Sitio } \\
\text { Natura } \\
\quad 1\end{array}$ & Ríos & Fuente & $\begin{array}{c}X: 752959 \\
Y: 9810199\end{array}$ & $\begin{array}{l}\text { Fuente y acumulación de agua de } \\
\text { considerable caudal que brota desde la } \\
\text { tierra, su coloración es oscura y profunda } \\
\text { al fondo, por lo que los pobladores han } \\
\text { tejido creencias acerca del lugar. El sitio } \\
\text { es de gran importancia para los } \\
\text { pobladores que habitan cerca, debido a } \\
\text { que llevan esta agua para solventar sus } \\
\text { necesidades diarias. }\end{array}$ & $\begin{array}{l}\text { En proceso de } \\
\text { deterioro }\end{array}$ & I \\
\hline 6 & $\begin{array}{l}\text { Lagun } \\
\text { a Paila } \\
\text { Kocha }\end{array}$ & $\begin{array}{l}\text { Sitio } \\
\text { Natura } \\
\quad 1\end{array}$ & $\begin{array}{l}\text { Amb } \\
\text { iente } \\
\text { Lacu }\end{array}$ & Cocha & $\begin{array}{c}\text { X: } 752958 \\
\text { Y: } 9809339\end{array}$ & $\begin{array}{l}\text { Su nombre se debe a que ésta tiene la } \\
\text { forma de una paila (utensillo de cocina), } \\
\text { los pobladores indican que al medio día }\end{array}$ & Alterado & I \\
\hline
\end{tabular}


stre

\begin{tabular}{|c|c|c|c|c|c|}
\hline \multicolumn{6}{|c|}{ stre } \\
\hline 7 & $\begin{array}{c}\text { Ruinas } \\
\text { de la } \\
\text { vivien } \\
\text { da de } \\
\text { Fernan } \\
\text { do } \\
\text { Daquil } \\
\text { ema }\end{array}$ & $\begin{array}{c}\text { Manife } \\
\text { stación } \\
\text { Cultur } \\
\text { al }\end{array}$ & $\begin{array}{c}\text { Etno } \\
\text { grafí } \\
\text { a }\end{array}$ & $\begin{array}{c}\text { Arquit } \\
\text { ectura } \\
\text { Vernác } \\
\text { ula }\end{array}$ & $\begin{array}{c}X: 752989 \\
Y: 9809492\end{array}$ \\
\hline
\end{tabular}

exactamente a las 12 aparece una paila, por lo que se cree que es encantada. La cantidad de agua va disminuyendo durante todo el año, sin embargo esta nunca se seca, la gente de la comunidad asegura que cuando la laguna esta con poca agua indica que muy pronto empezarán las lluvias.

Se cree que el sitio corresponde a los restos de una construcción que asemeja a una vivienda y que fue el lugar donde vivió el célebre Fernando Daquilema. Se

En proceso de deterioro puede observar paredes hechas de cancagua y piedra que tienen un grosor de entre 0,80 y $1 \mathrm{~m}$. En el entorno del sitio existen grandes espacios de terreno destinados al uso agrícola.

Todas las paredes de las instalaciones están construidas con bloques de cancagua y los techos son de paja, ubicada sobre una loma donde antiguamente sus moradores lo consideraban como un sitio estratégico para adorar al sol, así como también de observación y un punto de encuentro entre las comunidades. Dentro del museo se puede observar la vestimenta y accesorios autóctonos de Cacha, los utensillos más antiguos, técnicas artesanales e historia.

Es una iglesia católica, construida hace unos 35 años aproximadamente, con

bloques tallados de cancagua, la puerta es de madera y el techo por dentro está

Manife

stación

$\begin{array}{ccc}\text { Hist } & \text { Arquit } & \\ \text { órica } & \text { ectura } & \text { X: } 755619 \\ & \begin{array}{c}\text { religios } \\ \text { a }\end{array} & \text { Y: } 9811179 \\ & & \end{array}$
forrado con estera (tejido artesanal con fibra vegetal). A este sitio acuden miembros de todas las comunidades para celebrar las festividades religiosas como bautizos, matrimonios, comuniones y funerales.

Es una iglesia católica construida con cancagua, las paredes tienen un grosor de aproximadamente un metro, el techo está cubierto de teja y por dentro se encuentra forrado con estera, carrizos y chaguarqueros (tipo de vigas), en el Altar se encuentra una roca donde reposa la Virgen María. La construcción fue remodelada hace poco en donde las paredes internas fueron revestidas con cemento. Es utilizado por la comunidad en celebraciones.

Son las ruinas de la iglesia más antigua de Cacha con más de 100 años de antigüedad; lo impresionante de este sitio es la arquitectura, realizada principalmente con materiales propios de la zona; bloques de cancagua con un grosor de un metro y cubierta de cementina, presenta ventanales interiores solamente hasta la mitad de la pared es decir no tienen salida, actualmente no
En proceso de deterioro

En proceso de deterioro cuenta con techo. 


\begin{tabular}{|c|c|c|c|c|c|c|c|}
\hline 12 & $\begin{array}{l}\text { Rumi } \\
\text { Wasi }\end{array}$ & $\begin{array}{c}\text { Manife } \\
\text { stación } \\
\text { Cultur } \\
\text { al }\end{array}$ & $\begin{array}{l}\text { Etno } \\
\text { grafí } \\
\text { a }\end{array}$ & $\begin{array}{c}\text { Arquit } \\
\text { ectura } \\
\text { vernác } \\
\text { ula }\end{array}$ & $\begin{array}{c}X: 754631 \\
Y: 9812717\end{array}$ & $\begin{array}{l}\text { El nombre deriva de las palabras } \\
\text { Kichwas Rumi=Piedra y Wasi=Casa } \\
\text { (Casa de piedra). Es una construcción } \\
\text { realizada a base de cancagua en forma de } \\
\text { una choza. Ocupa un área de dos metros } \\
\text { cuadrados y el grosor de las paredes tiene } \\
\text { alrededor de } 30 \mathrm{~cm} \text {. La puerta tiene una } \\
\text { dimensión de } 1,60 \text { por } 1 \mathrm{~m} \text {. Los } \\
\text { pobladores creen que fueron construidos } \\
\text { para almacenar granos y alimentos o } \\
\text { como refugio para la lluvia o el sol. }\end{array}$ & $\begin{array}{l}\text { En proceso de } \\
\text { deterioro }\end{array}$ \\
\hline
\end{tabular}

Nota: JRQ equivale a Jerarquía

Tabla $\mathrm{N}^{\circ}$ 3. Resumen del Patrimonio cultural inmaterial

\begin{tabular}{cccc}
\hline $\begin{array}{c}\text { DENOMINACIÓN DEL } \\
\text { BIEN }\end{array}$ & $\begin{array}{c}\text { DETALLE DEL } \\
\text { SUBÁMBITO }\end{array}$ & ÁMBITO & SUBÁMBITO \\
\hline $\begin{array}{c}\text { Poncho Koko, fajas, cintas, } \\
\text { telares }\end{array}$ & Textilería & Textilería & $\begin{array}{c}\text { Técnicas artesanales } \\
\text { tradicionales }\end{array}$ \\
\hline Fiestas de Parroquialización & $\begin{array}{c}\text { Fiestas cívicas, fiestas } \\
\text { o ceremonias } \\
\text { religiosas }\end{array}$ & $\begin{array}{c}\text { Usos sociales, } \\
\text { rituales y actos } \\
\text { festivos }\end{array}$ & Fiestas \\
\hline Producción apícola & Apicultura & $\begin{array}{c}\text { Técnicas artesanales } \\
\text { tradicionales }\end{array}$ & $\begin{array}{c}\text { Técnicas artesanales } \\
\text { tradicionales }\end{array}$ \\
\hline Nativos de la parroquia & Grupo étnico & $\begin{array}{c}\text { Manifestación } \\
\text { Cultural }\end{array}$ & Etnografía \\
\hline
\end{tabular}

\section{Análisis de la demanda}

\section{Edad}

Tabla $N^{\circ}$ 4. Edad de potenciales clientes

\begin{tabular}{ccccc}
\hline & \multicolumn{2}{c}{ Turista nacional } & \multicolumn{2}{c}{ Turista extranjero } \\
\hline \multirow{2}{*}{ VARIABLE } & $\begin{array}{c}\text { FRECUENCIA } \\
\text { ABSOLUTA }\end{array}$ & $\begin{array}{c}\text { FRECUENCIA } \\
\text { RELATIVA }\end{array}$ & $\begin{array}{c}\text { FRECUENCIA } \\
\text { ABSOLUTA }\end{array}$ & $\begin{array}{c}\text { FRECUENCIA } \\
\text { RELATIVA }\end{array}$ \\
\hline $\mathbf{1 8 - \mathbf { 2 6 } \text { años }}$ & 29 & $28 \%$ & 56 & $21 \%$ \\
\hline $\mathbf{2 7}-\mathbf{3 5}$ años & 35 & $34 \%$ & 85 & $32 \%$ \\
\hline $\mathbf{3 6}-\mathbf{4 4}$ años & 21 & $20 \%$ & 77 & $29 \%$ \\
\hline $\mathbf{4 5 - 5 3}$ años & 12 & $12 \%$ & 32 & $12 \%$ \\
\hline $\mathbf{5 4 - 6 2}$ años & 4 & $4 \%$ & 8 & $3 \%$ \\
\hline$>\mathbf{6 3}$ & 2 & $2 \%$ & 8 & $3 \%$ \\
\hline TOTAL & 103 & $100 \%$ & 266 & $100 \%$ \\
\hline
\end{tabular}

La edad de los turistas nacionales encuestados comprende entre 27 35 años en su mayoría, con un 34\%, entre 18 - 26 años el $28 \%$, el $20 \%$ corresponde a las edades entre 36 - 44 años, el $12 \%$ a edades entre 45 - 53 años, entre 54 - 62 años el $4 \%$ y el $2 \%$ corresponde a más de 63 años de edad. Mientras que para turistas extranjeros la edad del 32\% de encuestados comprende entre 27 - 35 años, el $29 \%$ corresponde a las edades de 36 - 44 años, el $21 \%$ a edades comprendidas entre 18 - 26 años, el $12 \%$ entre $45-$ 53 años de edad y 3\% pertenece al grupo de edad entre 54 - 62 años y de 63 años en adelante. 


\section{Género}

Tabla $N^{\circ}$ 5. Género de los potenciales clientes

Turista nacional

\begin{tabular}{ccccc} 
VARIABLE & $\begin{array}{c}\text { FRECUENCIA } \\
\text { ABSOLUTA }\end{array}$ & $\begin{array}{c}\text { FRECUENCIA } \\
\text { RELATIVA }\end{array}$ & $\begin{array}{c}\text { FRECUENCIA } \\
\text { ABSOLUTA }\end{array}$ & $\begin{array}{c}\text { FRECUENCIA } \\
\text { RELATIVA }\end{array}$ \\
\hline Masculino & 47 & $46 \%$ & 117 & $44 \%$ \\
\hline Femenino & 56 & $54 \%$ & 149 & $56 \%$ \\
\hline TOTAL & 103 & $100 \%$ & 266 & $100 \%$ \\
\hline
\end{tabular}

El 54\% de los turistas nacionales encuestados son del género femenino y el $46 \%$ de género masculino. Mientras que en los turistas extranjeros el 56\% de encuestados son de género femenino y el $44 \%$ restante pertenecen al género masculino.

\section{Procedencia}

Tabla $N^{\circ}$ 6. Ciudad/país de procedencia de los potenciales clientes

\begin{tabular}{cccccc}
\hline & \multicolumn{2}{c}{ Turista nacional } & \multicolumn{2}{c}{ Turista extranjero } \\
\hline VARIABLE & $\begin{array}{c}\text { FRECUENC } \\
\text { IA }\end{array}$ & $\begin{array}{c}\text { FRECUENCI } \\
\text { ABSOLUTA }\end{array}$ & $\begin{array}{c}\text { VARIABL } \\
\text { RELATIVA }\end{array}$ & $\begin{array}{c}\text { FRECUENCI } \\
\text { E }\end{array}$ & $\begin{array}{c}\text { FRECUENCI } \\
\text { A }\end{array}$ \\
\hline Guayaquil & 39 & $38 \%$ & $\begin{array}{c}\text { Estados } \\
\text { unidos }\end{array}$ & 104 & $39 \%$ \\
Quito & 33 & $32 \%$ & Australia & 57 & $21 \%$ \\
\hline Ambato & 13 & $12 \%$ & Francia & 35 & $13 \%$ \\
\hline Machala & 6 & $6 \%$ & Alemania & 36 & $14 \%$ \\
\hline Esmeraldas & 8 & $8 \%$ & Canadá & 21 & $8 \%$ \\
\hline Tulcán & 24 & $4 \%$ & Japón & 13 & $5 \%$ \\
\hline TOTAL & 103 & $100 \%$ & TOTAL & 266 & $100 \%$ \\
\hline
\end{tabular}

El 38\% de los encuestados nacionales son de la ciudad de Guayaquil, el $32 \%$ proceden de la ciudad de Quito, el $12 \%$ pertenecen a la ciudad de Ambato, de la ciudad de Machala el 6\%, el 8\% pertenece a la ciudad de Esmeraldas y el 4\% son de la ciudad de Tulcán. Para los turistas extranjeros, el 39\% de encuestados son de Estados Unidos, el 21\% vienen de Australia, el $13 \%$ proceden de Francia, el 14\% son de Alemania, el 8\% corresponde a visitantes de Canadá y el 5\% restante pertenecen a Japón.

\section{Estado civil}

Tabla $\mathrm{N}^{\circ}$ 7. Estado civil de los potenciales clientes
Turista extranjero

\begin{tabular}{ccccc}
\hline VARIABLE & $\begin{array}{c}\text { FRECUENCIA } \\
\text { ABSOLUTA }\end{array}$ & $\begin{array}{c}\text { FRECUENCIA } \\
\text { RELATIVA }\end{array}$ & $\begin{array}{c}\text { FRECUENCIA } \\
\text { ABSOLUTA }\end{array}$ & $\begin{array}{c}\text { FRECUENCIA } \\
\text { RELATIVA }\end{array}$ \\
\hline Soltero & 70 & $68 \%$ & 184 & $69 \%$ \\
\hline Casado & 33 & $32 \%$ & 72 & $27 \%$ \\
\hline Viudo & & & 10 & $4 \%$ \\
\hline TOTAL & $\mathbf{1 0 3}$ & $\mathbf{1 0 0 \%}$ & $\mathbf{2 6 6}$ & $\mathbf{1 0 0 \%}$ \\
\hline
\end{tabular}


El 68\% de los encuestados nacionales manifiestan ser solteros y el $32 \%$ están casados. Mientras que en los turistas extranjeros el $69 \%$ de encuestados manifiestan ser solteros, el $27 \%$ son casados y el $4 \%$ de personas son viudos.

\section{Nivel de instrucción formal}

Tabla $\mathrm{N}^{\circ}$ 8. Nivel de instrucción educativa de los potenciales clientes

\begin{tabular}{ccccc}
\hline & \multicolumn{2}{c}{ Turista nacional } & \multicolumn{2}{c}{ Turista extranjero } \\
\hline VARIABLE & $\begin{array}{c}\text { FRECUENCIA } \\
\text { ABSOLUTA }\end{array}$ & $\begin{array}{c}\text { FRECUENCIA } \\
\text { RELATIVA }\end{array}$ & $\begin{array}{c}\text { FRECUENCIA } \\
\text { ABSOLUTA }\end{array}$ & $\begin{array}{c}\text { FRECUENCIA } \\
\text { RELATIVA }\end{array}$ \\
\hline Postgrado & 10 & $10 \%$ & 104 & $39 \%$ \\
\hline Superior & 74 & $72 \%$ & 152 & $57 \%$ \\
\hline Secundaria & 19 & $18 \%$ & 10 & $4 \%$ \\
\hline TOTAL & 103 & $100 \%$ & 266 & $100 \%$ \\
\hline
\end{tabular}

El 72\% de los turistas nacionales tienen estudios universitarios, el $18 \%$ poseen estudios secundarios y el 10\% tienen estudios de cuarto nivel. En los turistas extranjeros el $57 \%$ de encuestados tienen estudios universitarios, el 39\% cuentan con estudios de cuarto nivel, y el $4 \%$ han adquirido estudios secundarios.

\section{Ocupación}

Tabla $\mathrm{N}^{\circ}$ 9. Ocupación de los potenciales clientes

\begin{tabular}{ccccc}
\hline & \multicolumn{2}{c}{ Turista nacional } & \multicolumn{2}{c}{ Turista extranjero } \\
\hline VARIABLE & $\begin{array}{c}\text { FRECUENCIA } \\
\text { ABSOLUTA }\end{array}$ & $\begin{array}{c}\text { FRECUENCIA } \\
\text { RELATIVA }\end{array}$ & $\begin{array}{c}\text { FRECUENCIA } \\
\text { ABSOLUTA }\end{array}$ & $\begin{array}{c}\text { FRECUENCIA } \\
\text { RELATIVA }\end{array}$ \\
\hline $\begin{array}{c}\text { Empleado } \\
\text { privado }\end{array}$ & 56 & $54 \%$ & 168 & $63 \%$ \\
\hline $\begin{array}{c}\text { Empleado } \\
\text { publico }\end{array}$ & 23 & $22 \%$ & 45 & $17 \%$ \\
\hline Estudiante & 20 & $20 \%$ & 32 & $12 \%$ \\
\hline Jubilado & 4 & $4 \%$ & 21 & $8 \%$ \\
\hline TOTAL & 103 & $100 \%$ & 266 & $100 \%$ \\
\hline
\end{tabular}

De los encuestados nacionales el 54\% laboran en el sector privado, $22 \%$ en el sector público, el $20 \%$ son estudiantes y el $4 \%$ son jubilados. De los encuestados extranjeros el $63 \%$ laboran en el sector privado, el $17 \%$ son del sector público, el 12\% manifiestan ser estudiantes y el $8 \%$ son jubilados. 


\section{Motivo de viaje}

Tabla $N^{\circ} 10$. Motivo de viaje de los potenciales clientes

\begin{tabular}{ccccc}
\hline & \multicolumn{2}{c}{ Turista nacional } & \multicolumn{2}{c}{ Turista extranjero } \\
\hline VARIABLE & $\begin{array}{c}\text { FRECUENCIA } \\
\text { ABSOLUTA }\end{array}$ & $\begin{array}{c}\text { FRECUENCIA } \\
\text { RELATIVA }\end{array}$ & $\begin{array}{c}\text { FRECUENCIA } \\
\text { ABSOLUTA }\end{array}$ & $\begin{array}{c}\text { FRECUENCIA } \\
\text { RELATIVA }\end{array}$ \\
\hline Vacaciones & 62 & $60 \%$ & 194 & $73 \%$ \\
\hline Familia & 21 & $20 \%$ & 32 & $12 \%$ \\
\hline Amigos & 12 & $12 \%$ & 11 & $4 \%$ \\
\hline Negocios & 8 & $8 \%$ & 11 & $4 \%$ \\
\hline Estudios & & & 18 & $\mathbf{1 0 0 \%}$ \\
\hline TOTAL & $\mathbf{1 0 3}$ & $\mathbf{1 0 0 \%}$ & $\mathbf{2 6 6}$ & \\
\hline
\end{tabular}

Según los encuestados nacionales, el motivo de viaje para el $60 \%$ son vacaciones, el $20 \%$ viaja por visita familiar, el $12 \%$ por amigos y el $8 \%$ viajan por negocios. Para los turistas extranjeros el $73 \%$ manifiestan que viajan por vacaciones, el $12 \%$ viaja por familiares, el $4 \%$ viaja por amigos y negocios, mientras que el $7 \%$ viene por sus estudios.

\section{Tamaño del grupo}

Tabla N ${ }^{\circ} 11$. Acompañantes de los potenciales clientes

\begin{tabular}{ccccc}
\hline \multirow{2}{*}{ VARIABLE } & \multicolumn{2}{c}{ Turista nacional } & \multicolumn{2}{c}{ Turista extranjero } \\
& $\begin{array}{c}\text { FRECUENCIA } \\
\text { ABSOLUTA }\end{array}$ & $\begin{array}{c}\text { FRECUENCIA } \\
\text { RELATIVA }\end{array}$ & $\begin{array}{c}\text { FRECUENCIA } \\
\text { ABSOLUTA }\end{array}$ & $\begin{array}{c}\text { FRECUENCIA } \\
\text { RELATIVA }\end{array}$ \\
\hline Solo & 25 & $24 \%$ & 79 & $30 \%$ \\
\hline En pareja & 25 & $24 \%$ & 53 & $20 \%$ \\
\hline Amigos & 18 & $18 \%$ & 69 & $26 \%$ \\
\hline Familia & 35 & $34 \%$ & 65 & $24 \%$ \\
\hline TOTAL & 103 & $100 \%$ & 266 & $100 \%$ \\
\hline
\end{tabular}

Según los encuestados nacionales el 24\% viajan solos y en pareja, el $18 \%$ lo hacen con amigos y el $34 \%$ viajan junto a su familia. Para los Turistas extranjeros el $31 \%$ de los encuestados realizan sus viajes solos, el $25 \%$ lo hacen en compañía de sus amigos, el $24 \%$ lo hace con sus familiares y el 20\% lo hace en pareja.

\section{Organización del viaje}

Tabla $\mathrm{N}^{\mathrm{o}} 12$. Organización del viaje de los potenciales clientes

\begin{tabular}{ccccc}
\hline & \multicolumn{2}{c}{ Turistas nacionales } & \multicolumn{2}{c}{ Turistas extranjeros } \\
\hline VARIABLE & $\begin{array}{c}\text { FRECUENCIA } \\
\text { ABSOLUTA }\end{array}$ & $\begin{array}{c}\text { FRECUENCIA } \\
\text { RELATIVA }\end{array}$ & $\begin{array}{c}\text { FRECUENCIA } \\
\text { ABSOLUTA }\end{array}$ & $\begin{array}{c}\text { FRECUENCIA } \\
\text { RELATIVA }\end{array}$ \\
\hline Independiente & 95 & $92 \%$ & 67 & $25 \%$ \\
\hline $\begin{array}{c}\text { Operadora o } \\
\text { agencia de } \\
\text { viajes }\end{array}$ & 8 & $8 \%$ & 199 & $75 \%$ \\
\hline TOTAL & $\mathbf{1 0 3}$ & $\mathbf{1 0 0 \%}$ & $\mathbf{2 6 6}$ & $\mathbf{1 0 0 \%}$ \\
\hline
\end{tabular}


El 92\% de encuestados nacionales manifiestan que viajan de forma independiente y el 8\% restante viaja con alguna operadora o agencia de viajes. Para los turistas extranjeros la mayor parte de los encuestados es decir el $75 \%$ organiza sus viajes por medio de operadoras o agencias de viaje, el $25 \%$ viaja de forma independiente.

\section{Medios de comunicación}

Tabla $N^{\circ} 13$. Medios de comunicación utilizados por los potenciales clientes

\begin{tabular}{ccccc}
\hline & \multicolumn{2}{c}{ Turista nacional } & \multicolumn{2}{c}{ Turista extranjero } \\
\hline VARIABLE & $\begin{array}{c}\text { FRECUENCIA } \\
\text { ABSOLUTA }\end{array}$ & $\begin{array}{c}\text { FRECUENCIA } \\
\text { RELATIVA }\end{array}$ & $\begin{array}{c}\text { FRECUENCIA } \\
\text { ABSOLUTA }\end{array}$ & $\begin{array}{c}\text { FRECUENCIA } \\
\text { RELATIVA }\end{array}$ \\
\hline $\begin{array}{c}\text { Centros de } \\
\text { información } \\
\text { turística }\end{array}$ & 8 & $8 \%$ & 58 & $22 \%$ \\
\hline $\begin{array}{c}\text { Agencias y } \\
\text { operadoras de } \\
\text { viajes }\end{array}$ & 4 & $4 \%$ & & \\
\hline Radio/ Televisión & 8 & & & \\
\hline Prensa & 4 & $8 \%$ & 8 & $3 \%$ \\
\hline Revistas & 6 & $6 \%$ & 32 & $12 \%$ \\
\hline Web site & 37 & $36 \%$ & 106 & $40 \%$ \\
\hline Redes sociales & 25 & $24 \%$ & & $16 \%$ \\
\hline Amigos/familiares & 11 & $10 \%$ & 43 & $7 \%$ \\
\hline Guías de viaje & & & 19 & $\mathbf{1 0 0 \%}$ \\
\hline TOTAL & $\mathbf{1 0 3}$ & $\mathbf{1 0 0 \%}$ & $\mathbf{2 6 6}$ & \\
\hline
\end{tabular}

El 36\% de los encuestados nacionales se informan a través de sitios web, el $24 \%$ lo hace a través de redes sociales, el $10 \%$ se informa por medio de amigos y familiares, el $8 \%$ a través de centros de información turística y radio-televisión, el 6\% lo hace por revistas y el $4 \%$ se informa a través de agencias y operadoras de viajes y prensa. Para los turistas extranjeros el $40 \%$ de los encuestados utilizan los sitios web, el 22\% lo hace a través de centros de información turística, el $16 \%$ se entera a través de amigos y familiares, el $12 \%$ utilizan revistas, el $7 \%$ se informa en guías de viajes y el 3\% lo hace por radio y televisión.

\section{Preferencia de Turismo Rural Comunitario}

Tabla No 14. Aceptación de Turismo Rural comunitario

\begin{tabular}{ccccc}
\hline & \multicolumn{2}{c}{ Turista nacional } & \multicolumn{2}{c}{ Turista extranjero } \\
\hline VARIABLE & $\begin{array}{c}\text { FRECUENCIA } \\
\text { ABSOLUTA }\end{array}$ & $\begin{array}{c}\text { FRECUENCIA } \\
\text { RELATIVA }\end{array}$ & $\begin{array}{c}\text { FRECUENCIA } \\
\text { ABSOLUTA }\end{array}$ & $\begin{array}{c}\text { FRECUENCIA } \\
\text { RELATIVA }\end{array}$ \\
\hline Si & 93 & $90 \%$ & 253 & $95 \%$ \\
\hline No & 10 & $10 \%$ & 13 & $5 \%$ \\
\hline TOTAL & 103 & $100 \%$ & 266 & $100 \%$ \\
\hline
\end{tabular}


Al 90\% de los encuestados nacionales manifiestan que les gustaría realizar turismo rural comunitario, mientras que al $10 \%$ no le agrada esta modalidad de turismo. Para el turismo extranjero el 95\% de personas manifiestan que les agradaría realizar actividades de turismo rural comunitario, mientras que al 5\% de personas no les agrada esta modalidad de turismo.

\section{Actividades turísticas}

Tabla N 15. Actividades turísticas preferidas por los potenciales clientes

\begin{tabular}{ccccc}
\hline & \multicolumn{2}{c}{ Turista nacional } & \multicolumn{2}{c}{ Turista extranjero } \\
\hline VARIABLE & $\begin{array}{c}\text { FRECUENCIA } \\
\text { ABSOLUTA }\end{array}$ & $\begin{array}{c}\text { FRECUENCIA } \\
\text { RELATIVA }\end{array}$ & $\begin{array}{c}\text { FRECUENCIA } \\
\text { ABSOLUTA }\end{array}$ & $\begin{array}{c}\text { FRECUENCIA } \\
\text { RELATIVA }\end{array}$ \\
\hline $\begin{array}{c}\text { Convivencia } \\
\text { rural } \\
\text { comunitaria }\end{array}$ & 17 & $16 \%$ & 74 & $28 \%$ \\
\hline $\begin{array}{c}\text { Visita a un } \\
\text { centro de } \\
\text { interpretación }\end{array}$ & 15 & $14 \%$ & 40 & $15 \%$ \\
\hline $\begin{array}{c}\text { Caminatas } \\
\text { Camping }\end{array}$ & 10 & $10 \%$ & 53 & $20 \%$ \\
\hline $\begin{array}{c}\text { Visita a sitios } \\
\text { naturales }\end{array}$ & 14 & $20 \%$ & 18 & $7 \%$ \\
\hline Fotografías & 10 & $14 \%$ & 53 & $7 \%$ \\
\hline $\begin{array}{c}\text { Eventos } \\
\text { culturales } \\
\text { programados }\end{array}$ & 6 & $10 \%$ & 18 & \\
\hline $\begin{array}{c}\text { Recreación y } \\
\text { esparcimiento }\end{array}$ & 10 & $6 \%$ & & $3 \%$ \\
\hline TOTAL & 103 & $10 \%$ & 10 & \\
\hline
\end{tabular}

El 20\% de los encuestados nacionales prefieren realizar camping, al $16 \%$ le gustaría realizar actividades de convivencia rural comunitaria, el 14\% visitaría a un centro de interpretación y visitas a sitios naturales, al $10 \%$ le interesa las caminatas, fotografías y recreación y esparcimiento y el 6\% restante prefiere actividades como eventos culturales programados. Para los turistas extranjeros el $28 \%$ de los encuestados estarían dispuestos a realizar convivencia rural comunitaria, al $20 \%$ les agradaría realizar caminatas y visita a sitios naturales, el 15\% quiere visitar a un centro de interpretación, al $7 \%$ les gustaría realizar camping y fotografías y el 3\% restante se inclina por la recreación y esparcimiento. 


\section{Servicios turísticos demandados}

Tabla $\mathrm{N}^{\circ} 16$. Servicios turísticos demandados por los potenciales clientes

\begin{tabular}{ccccc}
\hline & \multicolumn{2}{c}{ Turista nacional } & \multicolumn{2}{c}{ Turistas extranjero } \\
\hline VARIABLE & $\begin{array}{c}\text { FRECUENCIA } \\
\text { ABSOLUTA }\end{array}$ & $\begin{array}{c}\text { FRECUENCIA } \\
\text { RELATIVA }\end{array}$ & $\begin{array}{c}\text { FRECUENCIA } \\
\text { ABSOLUTA }\end{array}$ & $\begin{array}{c}\text { FRECUENCIA } \\
\text { RELATIVA }\end{array}$ \\
\hline Hospedaje & 21 & $20 \%$ & 72 & $27 \%$ \\
\hline Alimentación & 25 & $24 \%$ & 61 & $23 \%$ \\
\hline Guianza & 16 & $16 \%$ & 56 & $21 \%$ \\
\hline Transporte & 31 & $30 \%$ & 24 & $9 \%$ \\
\hline $\begin{array}{c}\text { Venta de } \\
\text { artesanías }\end{array}$ & 10 & $10 \%$ & & $100 \%$ \\
\hline TOTAL & 103 & $100 \%$ & 266 & $20 \%$ \\
\hline
\end{tabular}

El 30\% de los encuestados nacionales manifiestan que requerirían del servicio de transporte, el 24\% desearían contar con el servicio de alimentación, al 20\% requerirían el servicio de alojamiento, el 16\% requieren guianza y el 10\% manifiestan que desearían contar con el servicio de ventas de artesanías. Para los turistas extranjeros el 27\% de los encuestados requieren los servicios de hospedaje, el 23\% les agradaría contar con el servicio de alimentación, el 21\% requieren guianza, el 20\% desean contar con el servicio de transporte y el 9\% les gustaría la venta de artesanías.

\section{Tipo de hospedaje en cabañas autóctonas}

Tabla $\mathrm{N}^{\circ} 17$. Aceptación del tipo de hospedaje por los potenciales clientes

\begin{tabular}{ccccc}
\hline & \multicolumn{2}{c}{ Turista nacional } & \multicolumn{2}{c}{ Turista extranjero } \\
\hline VARIABLE & $\begin{array}{c}\text { FRECUENCIA } \\
\text { ABSOLUTA }\end{array}$ & $\begin{array}{c}\text { FRECUENCIA } \\
\text { RELATIVA }\end{array}$ & $\begin{array}{c}\text { FRECUENCIA } \\
\text { ABSOLUTA }\end{array}$ & $\begin{array}{c}\text { FRECUENCIA } \\
\text { RELATIVA }\end{array}$ \\
\hline Si & 95 & $92 \%$ & 255 & $96 \%$ \\
\hline No & 8 & $8 \%$ & 11 & $4 \%$ \\
\hline TOTAL & 103 & $100 \%$ & 266 & $100 \%$ \\
\hline
\end{tabular}

$\mathrm{Al}$ 92\% de encuestados nacionales les gustaría hospedarse en cabañas autóctonas, mientras que al 8\% no le agrada este tipo de hospedaje. Para los turistas extranjeros al $96 \%$ de encuestados les agradaría hospedarse en cabañas autóctonas y al 4\% no les gusta este tipo de hospedaje.

Tiempo estimado de estadía

Tabla $\mathrm{N}^{\mathrm{o}}$ 18. Tiempo estimado de estadía por los potenciales clientes

\begin{tabular}{ccccc}
\hline & \multicolumn{2}{c}{ Turista nacional } & \multicolumn{2}{c}{ Turista extranjero } \\
\hline VARIABLE & $\begin{array}{c}\text { FRECUENCIA } \\
\text { ABSOLUTA }\end{array}$ & $\begin{array}{c}\text { FRECUENCIA } \\
\text { RELATIVA }\end{array}$ & $\begin{array}{c}\text { FRECUENCIA } \\
\text { ABSOLUTA }\end{array}$ & $\begin{array}{c}\text { FRECUENCIA } \\
\text { RELATIVA }\end{array}$ \\
\hline Un día & 35 & $34 \%$ & 13 & $5 \%$ \\
\hline Dos días & 47 & $46 \%$ & 120 & $45 \%$ \\
\hline Tres días & 15 & $14 \%$ & 82 & $31 \%$ \\
\hline $\begin{array}{c}\text { Más de tres } \\
\text { días }\end{array}$ & 6 & $6 \%$ & 51 & $19 \%$ \\
\hline TOTAL & 103 & $100 \%$ & 266 & $100 \%$ \\
\hline
\end{tabular}


Al 46\% de encuestados nacionales les gustaría permanecer dos días en la parroquia Cacha, el 34\% solo permanecería un día, el 14\% pasarían tres días y el 6\% se quedarían por más de 3 días. Para los turistas extranjeros el 45\% están dispuestos a pasar 2 días en la parroquia Cacha, el 31\% se alojaría por 3 días, el 19\% se quedaría más de 3 días y el 5\% estaría solo por un día.

\section{Estimación del gasto por paquete turístico/día}

Tabla $N^{\circ} 19$. Estimación del gasto por paquete turístico/día por los potenciales clientes

\begin{tabular}{ccccc}
\hline & \multicolumn{2}{c}{ Turista nacional } & \multicolumn{2}{c}{ Turista extranjero } \\
\hline VARIABLE & $\begin{array}{c}\text { FRECUENCIA } \\
\text { ABSOLUTA }\end{array}$ & $\begin{array}{c}\text { FRECUENCIA } \\
\text { RELATIVA }\end{array}$ & $\begin{array}{c}\text { FRECUENCIA } \\
\text { ABSOLUTA }\end{array}$ & $\begin{array}{c}\text { FRECUENCIA } \\
\text { RELATIVA }\end{array}$ \\
\hline $\mathbf{\$ 2 5 - 3 0}$ & 54 & $52 \%$ & 29 & $11 \%$ \\
\hline $\mathbf{\$ 3 1}-\mathbf{3 5}$ & 37 & $36 \%$ & 120 & $45 \%$ \\
\hline $\mathbf{\$ 3 6}-\mathbf{4 0}$ & 6 & $6 \%$ & 106 & $40 \%$ \\
\hline Más de $\mathbf{\$ 4 0}$ & 6 & $6 \%$ & 11 & $4 \%$ \\
\hline TOTAL & 103 & $100 \%$ & 266 & $100 \%$ \\
\hline
\end{tabular}

El 52\% de encuestados nacionales estarían dispuestos a pagar entre 25 - 30 dólares por persona por el paquete turístico por un día, el 36\% pagarían entre 31 - 35 dólares y el 6\% estiman pagar entre 36 - 40 dólares y más de 40 dólares. Para los turistas extranjeros el $45 \%$ de encuestados estarían dispuestos a pagar entre 31 - 35 dólares por persona por paquete por un día, el 40\% estiman pagar entre 36 - 40 dólares, el 11\% pagaría entre 25 30 dólares y el 4\% pagaría más de 40 dólares.

\section{Análisis de la competencia}

\section{Identificación de los competidores}

Para determinar la oferta sustitutiva se considera a las organizaciones que trabajan con proyectos de turismo comunitario en la provincia de Chimborazo (Tabla $\mathrm{N}^{\mathrm{o}}$ 30), agrupados en la formación de la Corporación para el Desarrollo del Turismo Comunitario en Chimborazo (CORDTUCH) como competencia directa.

Tabla $N^{\circ}$ 30. Caracterización de los centros de turismo comunitario de la CORDTUCH

\begin{tabular}{|c|c|c|c|c|}
\hline $\begin{array}{l}\text { NOMBRE } \\
\text { CTC }\end{array}$ & UBICACIÓN & $\begin{array}{l}\text { SERVICIOS TURISTICOS } \\
\text { OFERTADOS }\end{array}$ & $\begin{array}{c}\text { INGRESO } \\
\text { ANUAL } \\
\text { DE } \\
\text { TURISTAS }\end{array}$ & $\begin{array}{l}\text { ACTIVIDADES } \\
\text { PRINCIPALES } \\
\text { QUE OFRECEN }\end{array}$ \\
\hline $\begin{array}{c}\text { Asociación de } \\
\text { Guías RAZU } \\
\text { ÑAN }\end{array}$ & $\begin{array}{c}\text { Comunidad } \\
\text { Pulingui } \\
\text { Centro, } \\
\text { Parroquia San } \\
\text { Andrés, } \\
\text { Cantón } \\
\text { Guano. }\end{array}$ & $\begin{array}{c}\text { Hospedaje: Albergue } \\
\text { comunitario con } 5 \text { habitaciones } \\
\text { múltiples, capacidad para } 30 \\
\text { pax. } \\
\text { Restauración: Capacidad para } \\
20 \text { pax, ofrece desayunos, } \\
\text { almuerzos y cena. } \\
\text { Construcción con ladrillo y } \\
\text { eternit. }\end{array}$ & Sin registro & $\begin{array}{c}\text { Turismo de } \\
\text { naturaleza, Ruta al } \\
\text { último Hielero del } \\
\text { Chimborazo, } \\
\text { Observación de } \\
\text { aves y senderismo. }\end{array}$ \\
\hline
\end{tabular}


Precio: $\$ 20,00 \times$ noche, $\$ 8,50 \times$ plato.

Guianza: 4 guías nativos

Hospedaje: Albergue

comunitario, con 2 habitaciones

múltiples con capacidad para 8

Comunidad

Santa Lucia de

pax.

Restauración: Capacidad para

20 pax, ofrece desayunos, almuerzos y cenas.

Visión Futura

Chuquipogio,

ARTESA Parroquia San

Andrés,

Cantón

Guano.

Las construcciones son de ladrillo y teja.

Sin registro artesanías a base de paja.

Senderismo, paseo con llamas.

Precio: $\$ 20,00$ x noche, $\$ 8,50 x$ plato

Guianza: 3 guías nativos.

Elementos de alquiler: Caballos

\begin{tabular}{|c|c|c|c|c|}
\hline $\begin{array}{c}\text { Operación de } \\
\text { Turismo } \\
\text { CALSHI } \\
\text { GRANDE }\end{array}$ & $\begin{array}{c}\text { Comunidad } \\
\text { Calshi, } \\
\text { Parroquia San } \\
\text { Andrés, } \\
\text { Cantón } \\
\text { Guano. }\end{array}$ & $\begin{array}{c}\text { Hospedaje: Cabaña con } 2 \\
\text { habitaciones dobles, capacidad } \\
\text { para } 8 \text { pax. } \\
\text { Restauración: Capacidad para } \\
15 \text { pax. } \\
\text { Construcción mixta con adobe y } \\
\text { paja. } \\
\text { Precio: \$20,00 x noche, } \$ 8,50 \text { x } \\
\text { plato } \\
\text { Guianza: } 3 \text { guías nativos. }\end{array}$ & $\begin{array}{l}\text { Sin } \\
\text { registros }\end{array}$ & $\begin{array}{l}\text { Observación de } \\
\text { aves, caminatas. } \\
\text { Práctica de } \\
\text { actividades } \\
\text { agrícolas en } \\
\text { huertos orgánicos } \\
\text { familiares. } \\
\text { Actividades } \\
\text { espirituales, } \\
\text { religiosas y de } \\
\text { cosmovisión. }\end{array}$ \\
\hline $\begin{array}{c}\text { Asociación de } \\
\text { Guías Indígenas } \\
\text { de } \\
\text { GUARGUALLÁ }\end{array}$ & $\begin{array}{l}\text { Comunidad } \\
\text { Guarguallá } \\
\text { Chico, Cantón } \\
\text { Guamote, }\end{array}$ & $\begin{array}{c}\text { Hospedaje: Albergue } \\
\text { comunitario con } 3 \text { habitaciones, } \\
2 \text { dobles y } 1 \text { múltiple con } \\
\text { capacidad para } 15 \text { pax. } \\
\text { Restauración: Capacidad para } \\
15 \text { pax, ofrece desayunos, } \\
\text { almuerzos y cenas. } \\
\text { Construcción con ladrillo y } \\
\text { paja. } \\
\text { Precio: } \$ 20,00 \text { x noche, } \$ 8,50 \text { x } \\
\text { plato. } \\
\text { Guianza: } 5 \text { guías nativos, } 3 \\
\text { guías naturalistas. } \\
\text { Elementos de alquiler: Caballos }\end{array}$ & $\begin{array}{c}150 \\
\text { visitantes } \\
\text { entre } \\
\text { nacionales y } \\
\text { extranjeros. } \\
123 \\
\text { extranjeros } \\
27 \\
\text { nacionales }\end{array}$ & $\begin{array}{c}\text { Senderismo en la } \\
\text { ruta hacia el } \\
\text { volcán Sangay. } \\
\text { Convivencia } \\
\text { comunitaria } \\
\text { Observación de } \\
\text { aves. }\end{array}$ \\
\hline $\begin{array}{c}\text { Asociación de } \\
\text { Turismo CASA } \\
\text { CONDOR }\end{array}$ & $\begin{array}{c}\text { Comunidad } \\
\text { Pulingui San } \\
\text { Pablo, } \\
\text { Parroquia San } \\
\text { Juan, Cantón } \\
\text { Riobamba. }\end{array}$ & $\begin{array}{c}\text { Hospedaje: Cabañas con } 6 \\
\text { habitaciones con capacidad para } \\
36 \text { pax. } \\
\text { Restauración: Capacidad para } \\
30 \text { pax, ofrece desayunos, } \\
\text { almuerzos y cenas. } \\
\text { Construcciones con ladrillos y } \\
\text { eternit cubierto de paja. } \\
\text { Precio: } \$ 20,00 \text { x noche, } \$ 8,50 \text { x } \\
\text { plato. } \\
\text { Guianza: } 3 \text { guías nativos y } 20 \\
\text { guías naturalistas. } \\
\text { Elementos de alquiler: Caballos }\end{array}$ & $\begin{array}{c}589 \\
\text { visitantes } \\
\text { entre } \\
\text { nacionales y } \\
\text { extranjeros. } \\
530 \\
\text { extranjeros } \\
59 \\
\text { nacionales }\end{array}$ & $\begin{array}{l}\text { Aventura, } \\
\text { deportes, } \\
\text { cabalgatas, } \\
\text { caminatas. } \\
\text { Recorridos hacia } \\
\text { los refugios del } \\
\text { Chimborazo, } \\
\text { bosque de } \\
\text { Polylepis y el } \\
\text { Templo Machay. }\end{array}$ \\
\hline
\end{tabular}




\begin{tabular}{|c|c|c|c|c|}
\hline $\begin{array}{c}\text { Asociación de } \\
\text { mujeres } \\
\text { QUILLA } \\
\text { PACARI }\end{array}$ & $\begin{array}{c}\text { Comunidad } \\
\text { San Francisco } \\
\text { de } \\
\text { Cunuguachay } \\
\text { Parroquia } \\
\text { Calpi, Cantón } \\
\text { Riobamba. }\end{array}$ & $\begin{array}{c}\text { Hospedaje: Albergue } \\
\text { comunitario con } 4 \text { habitaciones } \\
\text { y capacidad para } 20 \text { pax. } \\
\text { Restauración: Capacidad para } \\
15 \text { pax, ofrece desayunos, } \\
\text { almuerzos y cenas. } \\
\text { Las construcciones son mixtas } \\
\text { de adobe y paja. } \\
\text { Precio: } \$ 20,00 \text { x noche, } \$ 8,50 \text { x } \\
\text { plato. } \\
\text { Guianza: } 2 \text { guías nativos. }\end{array}$ & Sin registro & $\begin{array}{l}\text { Convivencia } \\
\text { comunitaria, } \\
\text { caminatas. } \\
\text { Practica de } \\
\text { medicina } \\
\text { tradicional andina. } \\
\text { Elaboración de } \\
\text { artesanías. } \\
\text { Degustación de } \\
\text { comida típica. } \\
\text { Voluntariado. }\end{array}$ \\
\hline $\begin{array}{c}\text { SUMAK } \\
\text { KAWSAY }\end{array}$ & $\begin{array}{l}\text { Comunidad } \\
\text { Palacio Real, } \\
\text { Parroquia } \\
\text { Calpi, Cantón } \\
\text { Riobamba }\end{array}$ & $\begin{array}{l}\text { Hospedaje: No cuenta con el } \\
\text { servicio. } \\
\text { Restauración: Capacidad para } \\
50 \text { pax. Ofrece almuerzos y } \\
\text { platos especiales con carne de } \\
\text { llama. } \\
\text { Las construcciones son de } \\
\text { ladrillo y paja. } \\
\text { Precio: } \$ 8,50 \text { x plato } \\
\text { Guianza: } 6 \text { guías nativos }\end{array}$ & $\begin{array}{c}2500 \\
\text { visitantes } \\
\text { entre } \\
\text { nacionales y } \\
\text { extranjeros. } \\
2125 \\
\text { extranjeros } \\
375 \\
\text { nacionales }\end{array}$ & $\begin{array}{c}\text { Senderismo } \\
\text { Paseos con llamas } \\
\text { Visita al museo de } \\
\text { la llama } \\
\text { Elaboración de } \\
\text { artesanías. }\end{array}$ \\
\hline
\end{tabular}

Se considera a Sumak Kausay como competencia relevante con 2500 visitantes anuales, en actividades como senderismo, paseos con llamas (Lama glama) y elaboración de artesanías.

\section{Demanda y competencia potencial}

Tabla N $\mathrm{N}^{\circ}$ 31. Demanda potencial para los próximos 6 años

\begin{tabular}{cccc}
\hline AÑO & NACIONALES & EXTRANJEROS & TOTAL \\
\hline $\mathbf{2 0 1 5}$ & 2599 & 7053 & 9652 \\
\hline $\mathbf{2 0 1 6}$ & 2963 & 8041 & 11004 \\
\hline $\mathbf{2 0 1 7}$ & 3378 & 9166 & 12544 \\
\hline $\mathbf{2 0 1 8}$ & 3851 & 10450 & 14301 \\
\hline $\mathbf{2 0 1 9}$ & 4390 & 11913 & 16303 \\
\hline $\mathbf{2 0 2 0}$ & 5005 & 13580 & 18585 \\
\hline
\end{tabular}

Para el año 2015 habrá una demanda de 9652 turistas y para el año 2020 se proyecta a 18585 turistas.

Tabla $\mathrm{N}^{\circ}$ 32. Oferta potencial para los próximos 6 años

\begin{tabular}{cccc}
\hline AÑO & NACIONALES & EXTRANJEROS & TOTAL \\
\hline $\mathbf{2 0 1 5}$ & 526 & 3167 & 3692 \\
\hline $\mathbf{2 0 1 6}$ & 599 & 3610 & 4209 \\
\hline $\mathbf{2 0 1 7}$ & 683 & 4116 & 4799 \\
\hline $\mathbf{2 0 1 8}$ & 779 & 4692 & 5471 \\
\hline $\mathbf{2 0 1 9}$ & 888 & 5349 & 6236 \\
\hline $\mathbf{2 0 2 0}$ & 1012 & 6098 & 7110 \\
\hline
\end{tabular}

La oferta para el 2015 será de 3692 personas, para el 2020 habrá 7110 turistas en las diferentes dependencias de la CORDTUCH. 


\section{Demanda insatisfecha}

Tabla $\mathrm{N}^{\circ}$ 32. Oferta potencial para los próximos 6 años

\begin{tabular}{cccc}
\hline AÑO & $\begin{array}{c}\text { TURISTAS } \\
\text { EXTRANJEROS }\end{array}$ & $\begin{array}{c}\text { TURISTAS } \\
\text { NACIONALES }\end{array}$ & TOTAL \\
\hline $\mathbf{2 0 1 4}(\mathbf{0})$ & 3409 & 1819 & 5228 \\
\hline $\mathbf{2 0 1 5}$ & 3886 & 2074 & 5960 \\
\hline $\mathbf{2 0 1 6}$ & 4430 & 2364 & 6794 \\
\hline $\mathbf{2 0 1 7}$ & 5051 & 2695 & 7746 \\
\hline $\mathbf{2 0 1 8}$ & 5758 & 3072 & 8830 \\
\hline $\mathbf{2 0 1 9}$ & 6564 & 3502 & 10066 \\
\hline $\mathbf{2 0 2 0}$ & 7483 & 3993 & 11475 \\
\hline
\end{tabular}

Para el 2015 la demanda insatisfecha es de 5960 turistas y para el 2020 será de 11475 turistas.

\section{Diseño técnico del producto}

El producto está estructurado en torno al Centro Turístico Pucará Tambo y a los resultados obtenidos en el estudio de mercado destacando la convivencia rural comunitaria y complementando con todos los atractivos identificados en la parroquia.

Paquete $\mathrm{N}^{\circ}$ 1. Pamba Mesa

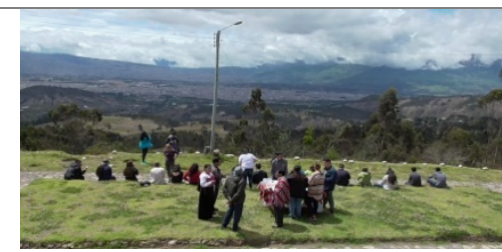

Foto 1. Pamba mesa

Modalidad:

Estilo

Tiempo de duración:

Grado de dificultad:

Precio:

\section{PUCARAlambo}

Centro Cultural y Turístico
Turismo cultural

1 día

Medio

14,40 (por pax a partir de 10 personas)

17,00 (por pax para 6 personas)

20,25 (por pax para 4 personas)

\section{ITINERARIO}

HORA

07H30

08H30

\section{ACTIVIDADES}

Arribo al Centro Turístico Pucará Tambo

Desayuno

Inicio de las actividades

Visita al Museo Etnográfico Cacha

Interpretación socio - cultural

Fotografía sin flash

Paseo por el jardín botánico del CT Pucará Tambo

Interpretación ambiental

Práctica de alimentación a los animales de granja 
Reconocimiento y explicación de plantas medicinales

Ceremonia ancestral con el Yachak

09H00

Preparación para la ceremonia (meditación)

Purificación con plantas medicinales

Práctica de convivencia comunitaria

Elaboración de la máchica en piedra de moler

09H30

Elaboración y Preparación de las humitas en leña

Preparación del chapo

Preparación para el Pamba Mikuy

$13 \mathrm{H} 00$

Pamba Mikuy

Fin del servicio

El paquete incluye:

\begin{tabular}{cc}
\hline Alimentación: & Almuerzo \\
\hline Guianza: & Guía nativo \\
\hline Fotografía: & Digital \\
\hline Material informativo: & Tríptico \\
\hline
\end{tabular}

Costo del paquete

\begin{tabular}{|c|c|c|c|c|c|}
\hline \multirow{2}{*}{ COSTOS GENERALES } & \multirow{2}{*}{ CANTIDAD } & \multirow{2}{*}{$\begin{array}{l}\text { PREC. } \\
\text { UNIT }\end{array}$} & \multicolumn{3}{|c|}{ RANGOS DE PAX } \\
\hline & & & 4 & 6 & 10 \\
\hline Yachak & 1 & 20 & 20 & 20 & 20 \\
\hline Leña & 1 & 3 & 6 & 6 & 6 \\
\hline TOTAL COSTOS GENERALES & & 3 & 26 & 26 & 26 \\
\hline \multicolumn{6}{|c|}{ COSTOS INDIVIDUALES } \\
\hline Ingreso CT PT & 1 & 1 & 1 & 1 & 1 \\
\hline Almuerzo (Ingredientes) & 1 & 6 & 6 & 6 & 6 \\
\hline $\begin{array}{l}\text { TOTAL COSTOS } \\
\text { INDIVIDUALES }\end{array}$ & & 7 & 7 & 7 & 7 \\
\hline \multicolumn{6}{|c|}{ COSTOS TOTALES POR PERSONA } \\
\hline TOTAL COSTOS GENERALES & & & 26 & 26 & 26 \\
\hline $\begin{array}{l}\text { TOTAL COSTOS } \\
\text { INDIVIDUALES }\end{array}$ & & & 7 & 7 & 7 \\
\hline TOTAL DE COSTOS & & & 33 & 33 & 33 \\
\hline Gastos administrativos (10\%) & & & 1,35 & 1,13 & 0,96 \\
\hline $\begin{array}{c}\text { Gastos de depreciación y venta } \\
(\mathbf{1 0 \% )}\end{array}$ & & & 1,35 & 1,13 & 0,96 \\
\hline Margen de rango (utilidad) $20 \%$ & & & 0,8 & 0,8 & 0,8 \\
\hline PRECIO NETO & & & 20,25 & 17,00 & 14,40 \\
\hline
\end{tabular}


Paquete $\mathrm{N}^{\circ}$ 2. Pakcha Purina
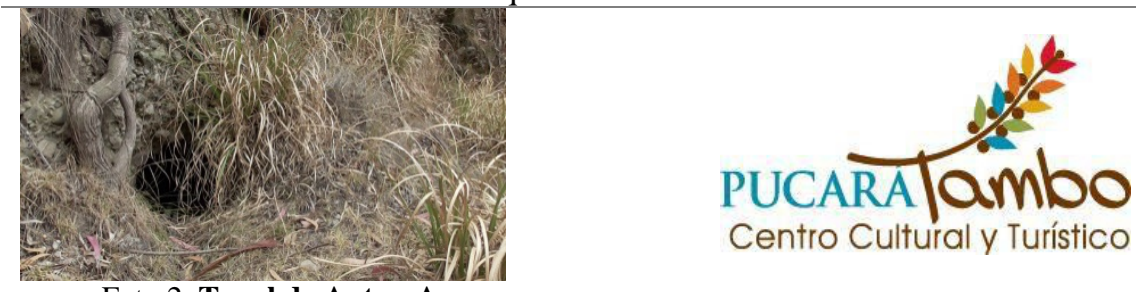

Foto 2. Tunel de Antun Aya

\begin{tabular}{|c|c|}
\hline Modalidad: & Ecoturismo \\
\hline Estilo & Trekking \\
\hline Tiempo de duración: & 1 día \\
\hline Grado de dificultad: & Medio \\
\hline Precio: & $\begin{array}{l}\text { 21,18 (por pax a partir de } 10 \text { personas) } \\
\text { 24,94 (por pax para } 6 \text { personas) } \\
\text { 29,65 (por pax para } 4 \text { personas) }\end{array}$ \\
\hline \multicolumn{2}{|r|}{ ITINERARIO } \\
\hline HORA & ACTIVIDADES \\
\hline 07H30 & $\begin{array}{l}\text { Concentración y salida desde Riobamba } \\
\text { Charla introductoria, bienvenida } \\
\text { Explicación del itinerario }\end{array}$ \\
\hline 08H00 & $\begin{array}{c}\text { Arribo al Centro Turístico Pucará Tambo } \\
\text { Desayuno }\end{array}$ \\
\hline 09H00 & $\begin{array}{c}\text { Visita al Museo Etnográfico Cacha } \\
\text { Interpretación socio - cultural } \\
\text { Fotografía sin flash } \\
\end{array}$ \\
\hline 09Н30 & $\begin{array}{l}\text { Paseo por el jardín botánico de Pucará Tambo } \\
\text { Interpretación ambiental } \\
\text { Práctica de alimentación a los animales de granja } \\
\text { Reconocimiento y explicación de plantas medicinales }\end{array}$ \\
\hline $\begin{array}{l}10 \mathrm{H} 00 \\
10 \mathrm{H} 45\end{array}$ & $\begin{array}{c}\text { Inicio del trekking } \\
\text { Arribo a la comunidad Machángara } \\
\text { Visita a la casa de la Familia Duchicela } \\
\text { Interpretación socio - cultural } \\
\text { Visita al monumento a Cacha } \\
\text { Interpretación histórica } \\
\text { Visita a la Iglesia de Cacha }\end{array}$ \\
\hline $10 \mathrm{H} 30$ & $\begin{array}{c}\text { Arribo a Obraje } \\
\text { Interpretación ambiental del hundimiento geológico del sector } \\
\text { Relato de la leyenda Antun Aya } \\
\text { Cruce del túnel Antun Aya } \\
\text { Caminata por la quebrada de Aulía }\end{array}$ \\
\hline $11 \mathrm{H} 30$ & Caminata por la afluente de Kocha Wayco \\
\hline & Box lunch \\
\hline $12 \mathrm{H} 00$ & Visita a la laguna Pakcha Wayco \\
\hline $12 \mathrm{H} 30$ & $\begin{array}{c}\text { Retorno al Centro Turístico Pucara Tambo } \\
\text { Ascenso al Pokyo del Baño de Purificación } \\
\text { Subida a Pucara Tambo }\end{array}$ \\
\hline $13 \mathrm{H} 30$ & $\begin{array}{l}\text { Arribo al Centro Turístico Pucara Tambo } \\
\text { Almuerzo (Opción para realizar camping) } \\
\text { Retorno a Riobamba }\end{array}$ \\
\hline $15 \mathrm{~h} 00$ & $\begin{array}{l}\text { Arribo a Riobamba } \\
\text { Fin del servicio }\end{array}$ \\
\hline
\end{tabular}




\section{El paquete incluye:}

\begin{tabular}{cc}
\hline Transporte: & Riobamba-Cacha ; Cacha-Riobamba \\
\hline Alimentación: & Desayuno, Box lunch, almuerzo \\
\hline Guianza: & Guía nativo \\
\hline Material informativo: & Tríptico \\
\hline
\end{tabular}

\section{Costo del paquete}

\begin{tabular}{|c|c|c|c|c|c|}
\hline \multirow{2}{*}{ COSTOS GENERALES } & \multirow{2}{*}{ CANTIDAD } & \multirow{2}{*}{$\begin{array}{l}\text { PREC. } \\
\text { UNIT }\end{array}$} & \multicolumn{3}{|c|}{ RANGOS DE PAX } \\
\hline & & & 4 & 6 & 10 \\
\hline Transporte & 1 & 10 & 10 & 10 & 10 \\
\hline Guía nativo & 1 & 30 & 30 & 30 & 30 \\
\hline TOTAL COSTOS GENERALES & & 40 & 40 & 40 & 40 \\
\hline \multicolumn{6}{|c|}{ COSTOS INDIVIDUALES } \\
\hline Desayuno & 1 & 3 & 3 & 3 & 3 \\
\hline Box lonch & 1 & 2 & 2 & 2 & 2 \\
\hline Ingreso CT PT & & 1 & 1 & 1 & 1 \\
\hline Almuerzo & 1 & 5 & 5 & 5 & 5 \\
\hline TOTAL COSTOS INDIVIDUALES & & & 11 & 11 & 11 \\
\hline \multicolumn{6}{|c|}{ COSTOS TOTALES POR PERSONA } \\
\hline TOTAL COSTOS GENERALES & & & 40 & 40 & 40 \\
\hline TOTAL COSTOS INDIVIDUALES & & & 11 & 11 & 11 \\
\hline TOTAL DE COSTOS & & & 51 & 51 & 51 \\
\hline Gastos administrativos (10\%) & & & 2,10 & 1,77 & 1,50 \\
\hline Gastos de depreciación y venta (10\%) & & & 2,10 & 1,77 & 1,50 \\
\hline Margen de rango (utilidad) 15\% & & & 0,85 & 0,85 & 0,85 \\
\hline PRECIO NETO & & & 29,65 & 24,94 & 21,18 \\
\hline \multicolumn{6}{|c|}{ Paquete $N^{\circ} 3$ Runa Kawsay (Vivencias del runa) } \\
\hline \multicolumn{6}{|l|}{ Foto 3. Siembra de plantas } \\
\hline Modalidad: & & Cultur & & & \\
\hline Estilo & \multicolumn{5}{|c|}{ Trekking - cultural } \\
\hline Tiempo de duración: & \multicolumn{5}{|c|}{2 días } \\
\hline Grado de dificultad: & \multicolumn{5}{|c|}{ Medio } \\
\hline Precio: & \multicolumn{5}{|c|}{$\begin{array}{l}\text { 62,52 (por pax a partir de } 10 \text { personas) } \\
\text { 70,60 (por pax para } 6 \text { personas) }\end{array}$} \\
\hline \multicolumn{6}{|c|}{ ITINERARIO } \\
\hline \multicolumn{6}{|c|}{ ACTIVIDADES } \\
\hline 07H30 & \multicolumn{5}{|c|}{$\begin{array}{l}\text { Concentración y salida desde Riobamba } \\
\text { Charla introductoria, bienvenida }\end{array}$} \\
\hline
\end{tabular}


Explicación del itinerario

Arribo al Centro Turístico Cultural Pucará Tambo

Chek in

08H00 Ambientación corporal con ejercicios básicos

Regulación de la temperatura corporal con la ingestión de agua medicinal proveniente de plantas aromáticas propias de la zona.

Desayuno

09H00

Visita al Museo Etnográfico Cacha Interpretación socio - cultural Fotografía sin flash

Paseo por el jardín botánico de Pucara Tambo

Interpretación ambiental

09H30 Práctica de alimentación a los animales de granja

Reconocimiento y explicación de plantas medicinales

\begin{tabular}{|c|c|}
\hline $\begin{array}{l}09 \mathrm{H} 45 \\
10 \mathrm{H} 00\end{array}$ & $\begin{array}{l}\text { Inicio del trekking } \\
\text { Arribo a la comunidad Machángara } \\
\text { Visita a la casa de la Familia Duchicela } \\
\text { Interpretación socio - cultural } \\
\text { Visita al monumento a Cacha } \\
\text { Interpretación histórica } \\
\text { Visita a la Iglesia de Cacha }\end{array}$ \\
\hline $11 \mathrm{H} 00$ & $\begin{array}{c}\text { Arribo a Obraje } \\
\text { Interpretación ambiental del hundimiento geológico del sector } \\
\text { Cruce del túnel Antun Aya } \\
\text { Relato de la leyenda Antun Aya } \\
\text { Caminata por la quebrada de Aulía }\end{array}$ \\
\hline $11 \mathrm{H} 45$ & $\begin{array}{l}\text { Visita a la laguna Paccha Wayco } \\
\text { Fotografías }\end{array}$ \\
\hline $12 \mathrm{H} 00-12 \mathrm{H} 15$ & Box Lunch en Paccha Wayco \\
\hline $12 \mathrm{H} 15$ & Caminata por la afluente de Kocha Wayco \\
\hline $13 \mathrm{H} 00-14 \mathrm{H} 00$ & $\begin{array}{c}\text { Arribo a la comunidad Pucará Quinche } \\
\text { Interpretación histórica de lo que fue la Laguna Kapac Kocha } \\
\text { Visita a los artesanos de la comunidad (Hilado de la lana de oveja y } \\
\text { enrollado del hilo) }\end{array}$ \\
\hline $14 \mathrm{H} 30$ & $\begin{array}{c}\text { Arribo a la comunidad Cachatón } \\
\text { Visita a Verde Cocha } \\
\text { Interpretación histórica de la Iglesia El Rosario } \\
\text { Interpretación ambiental del hundimiento geológico del sector }\end{array}$ \\
\hline $15 \mathrm{H} 00$ & $\begin{array}{l}\text { Salida en transporte al Cerro Chuyuk } \\
\text { Siembra de plantas nativas en el cerro }\end{array}$ \\
\hline $16 \mathrm{H} 00$ & Retorno al Pucará Tambo \\
\hline $19 \mathrm{H} 00$ & $\begin{array}{l}\text { Tiempo libre } \\
\text { Cena }\end{array}$ \\
\hline $20 \mathrm{H} 00$ & $\begin{array}{l}\text { Noche de Integración Cultural (cine) } \\
\text { Proyección de video "Artesanías de Cacha" } \\
\text { Proyección de video "Los hijos de Daquilema" }\end{array}$ \\
\hline $21 \mathrm{H} 00$ & $\begin{array}{l}\text { Descanso (opción en cabañas o carpas) } \\
\text { DIA } 2\end{array}$ \\
\hline 08H00 & Desayuno \\
\hline 09Н30 & $\begin{array}{l}\text { Arribo a la comunidad San Miguel de Quera } \\
\text { Visita a las fuentes de agua Quera Wayko } \\
\text { Interpretación ambiental } \\
\text { Parada en el monumento a Fernando Daquilema } \\
\text { Interpretación histórica } \\
\text { Visita a la Iglesia de Quera y Laguna }\end{array}$ \\
\hline
\end{tabular}


Arribo a los vestigios de la vivienda de Fernando Daquilema

Arribo a la comunidad Chacán Loma

11h00 Interpretación ambiental

Vista panorámica al paisaje

Fotografías

Visita a la iglesia de Balbanera

$11 \mathrm{H} 45$

Interpretación histórico - cultural

Fotografía

Retorno a Cacha

13H00 Visita al Rumi Wasi (casa de piedra)

13H30 Arribo a la comunidad Casa Loma

Visita al Balneario de Hualcopo Duchicela

14H00 Retorno al Pucará Tambo

$14 \mathrm{H} 30 \quad$ Almuerzo

$16 \mathrm{HOO}$

Chek out

$16 \mathrm{H} 15$

Despedida

$16 \mathrm{H} 30$

Retorno a Riobamba

Fin del servicio

\section{El paquete incluye:}

Transporte:

Riobamba-Cacha; Recorrido; Cacha-Riobamba

Alimentación:

Desayuno, Box lunch, almuerzo, cena

Guianza:

Guía nativo

Alojamiento:

Cabañas sencillas o múltiples

Material informativo:

Tríptico

Planta:

Planta nativa

Costo del paquete

\begin{tabular}{|c|c|c|c|c|c|}
\hline \multirow{2}{*}{ COSTOS GENERALES } & \multirow{2}{*}{ CANTIDAD } & \multirow{2}{*}{$\begin{array}{l}\text { PREC. } \\
\text { UNIT }\end{array}$} & \multicolumn{3}{|c|}{ RANGOS POR PAX } \\
\hline & & & 4 & 6 & 10 \\
\hline Guía nativo & 1 & 30 & 30 & 30 & 30 \\
\hline Transporte & 1 & 40,75 & 40,75 & 40,75 & 40,75 \\
\hline Entrada & 1 & 5 & 5 & 5 & 5 \\
\hline TOTAL COSTOS GENERALES & & 75,75 & 75,75 & 75,75 & 75,75 \\
\hline \multicolumn{6}{|c|}{ COSTOS INDIVIDUALES } \\
\hline Desayuno & 2 & 5,00 & 5,00 & 5,00 & 5,00 \\
\hline Almuerzo & 1 & 4,00 & 4,00 & 4,00 & 4,00 \\
\hline Box lunch & 1 & 2,00 & 2,00 & 2,00 & 2,00 \\
\hline Ingreso CT PT & 1 & 1,00 & 1,00 & 1,00 & 1,00 \\
\hline Cena & 1 & 3,50 & 3,50 & 3,50 & 3,50 \\
\hline Hospedaje & 1 & 15,00 & 15,00 & 15,00 & 15,00 \\
\hline Planta Nativa & 1 & 1,00 & 1,00 & 1,00 & 1,00 \\
\hline $\begin{array}{l}\text { TOTAL COSTOS } \\
\text { INDIVIDUALES }\end{array}$ & , & 31,50 & 31,50 & 31,50 & 31,50 \\
\hline \multicolumn{6}{|c|}{ COSTOS TOTALES POR PERSONA } \\
\hline TOTAL COSTOS GENERALES & & & 75,75 & 75,75 & 75,75 \\
\hline $\begin{array}{l}\text { TOTAL COSTOS } \\
\text { INDIVIDUALES }\end{array}$ & & & 31,5 & 31,5 & 31,5 \\
\hline
\end{tabular}




\begin{tabular}{cccc}
\hline TOTAL DE COSTOS & 107,25 & 107,25 & 107,25 \\
\hline Gastos administrativos (10\%) & 5,04 & 4,41 & 3,91 \\
\hline $\begin{array}{c}\text { Gastos de depreciación y venta } \\
(\mathbf{1 0 \% )}\end{array}$ & 5,04 & 4,41 & 3,91 \\
\hline Margen de rango (utilidad) $\mathbf{2 5 \%}$ & 0,75 & 0,75 & 0,75 \\
\hline PRECIO NETO & 80,70 & 70,60 & 62,52 \\
\hline
\end{tabular}

\section{Conclusion}

La Parroquia Cacha posee una gran riqueza cultural y natural, reflejados en sus tradiciones, celebraciones y cotidianidad, los mismos que le dan la potencialidad para desarrollar turismo y generar un desarrollo económico y social para sus comunidades.

El principal atractivo de la parroquia Cacha se basa en manifestaciones culturales permitiendo el desarrollo del turismo comunitario en esta zona rural, mencionando que también se cuenta con un amplio mercado potencial para la comercialización y venta de futuros productos ofertados por el Centro Turístico Pucará Tambo.

\section{References:}

Coordinación General de Estadística e Investigación del Ministerio de Turismo del Ecuador. (7 de Enero de 2015). Principales indicadores de turismo Diciembre 2014. Boletín No 12. Quito, Pichincha, Ecuador.

Boada, C. (2013). Nuestra megadiversidad desconocida. Revista Terraincognita. No 24.2 Recuperado de www.terrecuador,net/revista_24/24_megadiversidad.htm. 2013

Cioce, C., moreno, C., \& Ribeiro, F. (2007). Community tourism: montnha beija-flor dourado pilot project (microbasin of the sagrado river, Morretes, Paraná). Turismo-Visao e Açao, vol. 9 (2). Pp. 249- 266.

CODENPE (Consejo de Desarrollo de las Nacionalidades y Pueblos del Ecuador), 2012. Nacionalidades y pueblos del Ecuador. Recuperado de http://www.codenpe.gob.ec/index.php?option=com_content\&view=article\&i $\mathrm{d}=125 \&$ catid $=96$

Constitución de la República del Ecuador, (2008).

Coordinación General de Estadística e Investigación del Ministerio de Turismo del Ecuador. (20 de Abril de 2015). Boletín trimestral. Información relevante del turismo en el Ecuador. I Trimestre del año 2015. Quito, Pichincha, Ecuador.

Coordinación General de Estadística e Investigación del Ministerio de Turismo del Ecuador. (7 de Enero de 2015). Principales indicadores de turismo diciembre 2014. Boletín No 12. Quito, Pichincha, Ecuador.

Cruz, M. (2012). “Turismo, identidad y reivindicación sociocultural en Chile”. Turismo y Sostenibilidad: V Jornadas de Investigación en Turismo, Universidad de Sevilla, Sevilla. Pp. 127-147. 
INEC (Instituto Ecuatoriano de Estadísticas y Censo), 2010. Censo de Población y Vivienda 2010. Población indígena de la provincia de Chimborazo.

Ruiz, E., \& Solís, D. (2007). Turismo comunitario: Desarrollo y sostenibilidad social, Pp. 5-6,22 Quito, Editorial Abya_Yala; Pg: 32, 5, 6, 22, 11, 333

Gobierno Autónomo Descentralizado De La Provincia De Chimborazo. (2013). Plan de Ordenamiento territorial de Chimborazo. Atlas cartográfico. 2011. Pp. 3 Juan Pilco. Plan de salvaguardia de patrimonio cultural inmaterial en el ámbito del conocimiento y usos relacionados con la naturaleza y el universo, para la gestión turística sostenible de la microcuenca media y alta del rio Chimborazo. Escuela Superior Politécnica de Chimborazo. Facultad de Recursos Naturales. Riobamba. Pp 77, 272.

Ministerio de Turismo, (2014). Boletín de Estadísticas Turísticas 2010 2014. Recuperado de http://servicios.turismo.gob.ec/index.php/anuario-deestadisticas-turisticas/anuario-2010-2014/244

Ministerio de Turismo, (2014). Coordinación General de Estadística e Investigación. Principales indicadores de turismo Diciembre 2014. Recuperado de http://www.optur.org/estadisticas/Diciembre_boletin_2014.pdf

Organización Mundial del Turismo OMT, (2008). Entender el Turismo. Recuperado de http://media.unwto.org/es/content/entender-el-turismoglosario-basico

Organización Mundial del Turismo. (2 de Marzo de 2001). El desarrollo sostenible del turismo.

Prieto, M. (2011). Espacios en disputa: el turismo en Ecuador. FLACSO, Sede Ecuador, 1a edición. Quito - Ecuador.

SENPLADES. "Secretaría Nacional de Planificación y Desarrollo - Plan Nacional de Desarrollo / Plan Nacional para el Buen Vivir”. 2013-2017 Resolución 2 Registro Oficial Suplemento 78 de 11-sep-2013 Estado. (20132017) Pp. 13

World Travel \& Tourism Council, (2016). Impacto Económico del Viaje y el Turismo Actualización anual 2016. Recuperado de http://www.wttc.org//media/files/reports/economic\%20impact\%20research/2016\%20documents/e conomic\%20impact\%20summary\%202016_a4\%20web.pdf 